\title{
Hyperoside induces both autophagy and apoptosis in non-small cell lung cancer cells in vitro
}

\author{
Ting $\mathrm{FU}^{1}$, Ling WANG ${ }^{1}$, Xiang-nan $\mathrm{JIN}^{2}$, Hai-juan SUI ${ }^{2}$, Zhou LIU², Ying $\mathrm{JIN}^{2}$, * \\ ${ }^{1}$ Department of Special Requirement Wards, First Affiliated Hospital of Soochow University, Suzhou 215006, China; ${ }^{2}$ Department of \\ Pharmacology, Liaoning Medical University, Jinzhou 121001, China
}

\begin{abstract}
Aim: Hyperoside (quercetin-3-O- $\beta$-D-galactopyranoside) is a flavonol glycoside found in plants of the genera Hypericum and Crataegus, which exhibits anticancer, anti-oxidant, and anti-inflammatory activities. In this study we investigated whether autophagy was involved in the anticancer mechanisms of hyperoside in human non-small cell lung cancer cells in vitro.

Methods: Human non-small cell lung cancer cell line A549 was tested, and human bronchial epithelial cell line BEAS-2B was used for comparison. The expression of LC3-II, apoptotic and signaling proteins was measured using Western blotting. Autophagosomes were observed with MDC staining, LC3 immunocytochemistry, and GFP-LC3 fusion protein techniques. Cell viability was assessed using MTT assay.

Results: Hyperoside (0.5, 1, 2 mmol/L) dose-dependently increased the expression of LC3-II and autophagosome numbers in A549 cells, but had no such effects in BEAS-2B cells. Moreover, hyperoside dose-dependently inhibited the phosphorylation of Akt, mTOR, p70S6K and 4E-BP1, but increased the phosphorylation of ERK1/2 in A549 cells. Insulin (200 nmol/L) markedly enhanced the phosphorylation of Akt and decreased LC3-II expression in A549 cells, which were reversed by pretreatment with hyperoside, whereas the MEK1/2 inhibitor U0126 (20 $\mathrm{mol} / \mathrm{L})$ did not blocked hyperoside-induced LC3-II expression. Finally, hyperoside dose-dependently suppressed the cell viability and induced apoptosis in A549 cells, which were significantly attenuated by pretreatment with the autophagy inhibitor 3-methyladenine $(2.5 \mathrm{mmol} / \mathrm{L})$.

Conclusion: Hyperoside induces both autophagy and apoptosis in human non-small cell lung cancer cells in vitro. The autophagy is induced through inhibiting the Akt/mTOR/p70S6K signal pathways, which contributes to anticancer actions of hyperoside.
\end{abstract}

Keywords: non-small cell lung cancer; hyperoside; autophagy; apoptosis; insulin; U0126; 3-methyladenine; PI3K/Akt/mTOR/p70S6K

Acta Pharmacologica Sinica (2016) 37: 505-518; doi: 10.1038/aps.2015.148; published online 7 Mar 2016

\section{Introduction}

Lung cancer is one of the most common malignant tumors in the world. Non-small cell lung cancer (NSCLC) accounts for approximately $85 \%$ of all lung cancers. Despite the combination of surgery, chemotherapy, and radiotherapy, NSCLC patients still have poor prognoses. Therefore, there is an urgent need to develop new therapeutic strategies.

Most anti-cancer drugs are associated with the induction of programmed cell death (PCD). Apoptosis, also known as type I cell death, was regarded as the principal cell death mechanism $^{[1,2]}$. However, cancer cells trigger multiple pathways to escape from apoptosis ${ }^{[3]}$. Autophagy is known as a nonapoptotic (type II) PCD. It has been reported that excessive stimulation of autophagy through over-expression of beclin 1

\footnotetext{
* To whom correspondence should be addressed.

E-mail jyjinying1130@163.com

Received 2015-10-06 Accepted 2015-12-07
}

suppresses tumorigenesis ${ }^{[4]}$. Autophagy has a complex relationship with apoptosis, especially in tumor cell lines ${ }^{[5]}$. Autophagy functions as a tumor suppression mechanism by removing damaged organelles/proteins and limiting cell growth and genomic instability ${ }^{[6]}$. Several studies have shown that autophagy can enhance caspase-dependent cell death ${ }^{[7]}$.

Autophagy is characterized by the large-scale sequestration of portions of the cytoplasm in autophagosomes, giving the cell a characteristic vacuolated appearance ${ }^{[8]}$. During autophagy, a phagophore sourced from endoplasmic reticulum or plasma membrane sequesters the cellular contents and elongates to form autophagosomes, depending on autophagyrelated gene (Atg) proteins ${ }^{[9,10]}$. Then, the autophagosomes fuse with lysosomes to form autolysosomes ${ }^{[11]}$.

Phosphoinositide 3-kinase (PI3K)/protein kinase B (Akt) signaling is frequently activated in various types of cancers and hence represents a major cell survival pathway ${ }^{[12]}$. One well-known signaling pathway downstream of PI3K/Akt 
is the mammalian target of rapamycin (mTOR) pathway. mTOR serves as a central regulator of autophagy and forms two distinct signaling complexes, known as mTORC1 and mTORC2 ${ }^{[13]}$. The best-characterized downstream effectors of mTORC1 are p70S6 kinase (p70S6K) and the eukaryotic initiation factor 4E binding protein 1 (4E-BP1), which control protein translation ${ }^{[14]}$. Constitutive activation of the PI3K/Akt/ mTOR pathway occurs in 90\% of NSCLC cell lines ${ }^{[15]}$. Several anti-cancer agents are known to inhibit the PI3K/Akt/mTOR/ p70S6K pathway and simultaneously activate extracellular signal-regulated kinase (ERK1/2), resulting in induction of autophagy in tumor cell lines ${ }^{[16,17]}$. In accordance with this observation, treatment with the mTOR inhibitor rapamycin was associated with a $90 \%$ reduction in carcinogen-induced lung tumors in a murine model ${ }^{[18]}$.

Flavonoids are a group of the most abundant polyphenols in our daily diet and display a wide range of pharmacological properties ${ }^{[19]}$. Quercetin-3-O- $\beta$ - $D$-galactopyranoside, also known as hyperoside, is a flavonol glycoside mainly found in plants of the genera Hypericum and Crataegu ${ }^{[20]}$. Previous studies have shown that hyperoside has anti-oxidant ${ }^{[21]}$, anticancer ${ }^{[22,23]}$ and anti-inflammatory activities ${ }^{[24-26]}$. Furthermore, hyperoside produced anti-cancer effects through inducing apoptosis $^{[22]}$ and inhibiting of oncogenic microRNA-27a ${ }^{[27]}$. However, whether hyperoside induces autophagy, and the role it plays in cell death in human lung cancer cells, remain unclear. In this study, we aimed to investigate the effects of hyperoside-induced autophagy in the A549 cell line and its underlying mechanisms, focusing on the role of the PI3K/ $\mathrm{Akt} / \mathrm{mTOR}$ and ERK1/2 signaling pathways in hyperosideinduced autophagy.

\section{Materials and methods Reagents}

Hyperoside (MW: 464.38, HPLC $\geq 98 \%$ ) was purchased from Nanjing Spring \& Autumn Biological Engineering Co, Ltd (Nanjing, China). Hyperoside was dissolved in aqueous DMSO and delivered to cells in media containing this solvent at a final concentration of $0.1 \%(v / v)$. U0126 and rapamycin were obtained from Calbiochem (Darmstadt, Germany). 3-Methyladenine (3-MA) was from Sigma-Aldrich Chemical Co (St Louis, MO, USA). E64d, pepstatin A, and insulin were from Sigma Chemical Co (St Louis, MO, USA). Triciribine was from Santa Cruz Biotechnology (Santa Cruz, CA, USA). Monodansylcadaverine (MDC) was purchased from Nanjing KeyGEN Biotech Co, Ltd (Nanjing, China). The 5-bromo2 -deoxyuridine (BrdU) cell proliferation assay kit was from Merck Millipore.

\section{Cell culture}

The human NSCLC cell line A549 was obtained from Rochen Pharma Co, Ltd (Shanghai, China). The normal human bronchial epithelial cell line BEAS-2B was from Shanghai MEIXUAN Biological Science and Technology Ltd (Shanghai, China). The cells were cultured and grown in Dulbecco's modified Eagle's medium (DMEM, Gibco, Grand Island,
NY, USA) supplemented with $10 \%$ fetal bovine serum (FBS), (Gibco, USA) and $100 \mathrm{U} / \mathrm{mL}$ penicillin-streptomycin mixed antibiotics at $37^{\circ} \mathrm{C}$ in a humidified $5 \% \mathrm{CO}_{2}$ incubator.

\section{Cell viability assays}

Cell viability was measured by the 3-(4,5-dimethylthiazol2-yl)-2,5-diphenyltetrazolium bromide (MTT) method. Briefly, A549 cells were seeded in a 96-well plate at a density of $5 \times 10^{3}$ cells/well containing $100 \mu \mathrm{L}$ of culture medium. After $24 \mathrm{~h}$ incubation, the medium was carefully removed, and $100 \mu \mathrm{L}$ of fresh medium containing various concentrations of hyperoside $(0.1,0.5,1$, and $2 \mathrm{mmol} / \mathrm{L})$ was added to the wells. The cells were continuously treated with hyperoside for 24 or $48 \mathrm{~h}$. Then, the medium was carefully removed, and $100 \mu \mathrm{L}$ of fresh medium containing $0.5 \mathrm{mg} / \mathrm{mL}$ MTT was added to the wells. After $4 \mathrm{~h}$ incubation, the dark blue formazan crystals formed in intact cells were dissolved in DMSO, and the absorbance at $570 \mathrm{~nm}$ was read using a microplate reader (Thermo, Waltham, MA, USA). Absorbance of untreated cells was considered $100 \%$.

\section{BrdU cell proliferation assay}

The BrdU assay was used to examine the effect of hyperoside on the proliferation of A549 cells. A cell proliferation ELISA was used to measure the incorporation of BrdU during DNA synthesis following the manufacturer's protocols. Briefly, A549 cells were seeded in a 96-well plate at a density of $5 \times 10^{3}$ cells/well containing $100 \mu \mathrm{L}$ of culture medium. After $24 \mathrm{~h}$ incubation, the medium was carefully removed, and $100 \mu \mathrm{L}$ of fresh medium containing various concentrations of hyperoside $(0.1,0.5,1$, and $2 \mathrm{mmol} / \mathrm{L})$ was added to the wells for $48 \mathrm{~h}$. Eighteen hours before termination of the experiments, BrdU $(10 \mu \mathrm{mol} / \mathrm{L})$ was added to the culture medium. Then, the BrdU-labeled cells were fixed, and the DNA was denatured in fixative solution for $30 \mathrm{~min}$ at room temperature. The cells were then incubated with peroxidase-conjugated anti-BrdU antibody for $1 \mathrm{~h}$ at room temperature, followed by washing three times with washing solution. The immune complex was detected using a 3,3',5,5'-tetramethylbenzidine substrate reaction, and absorbance was measured at $450 \mathrm{~nm}$.

\section{MDC staining of autophagic vacuoles}

MDC staining of autophagic vacuoles was performed for autophagy analysis as previously described ${ }^{[28]}$. A549 cells or BEAS-2B cells were seeded onto coverslips placed onto a 24-well plate at a density of $1 \times 10^{4}$ cells $/ \mathrm{mL} 24 \mathrm{~h}$ before treatment and were incubated overnight at $37^{\circ} \mathrm{C}$. After a $48 \mathrm{~h}$ treatment with hyperoside $(2 \mathrm{mmol} / \mathrm{L})$, the cells were incubated for $20 \mathrm{~min}$ with $\mathrm{MDC}(0.05 \mathrm{mmol} / \mathrm{L})$ at $37^{\circ} \mathrm{C}$ and were then washed four times with PBS. Autophagic vacuoles were observed under a fluorescence microscope.

\section{Western blotting analysis}

Western blot analysis was performed as previously described $^{[29]}$. Whole cell lysates were prepared from A549 cells or BEAS-2B cells cultured in 6-well dishes using radioim- 
munoprecipitation assay (RIPA) lysis buffer in the presence of protease inhibitors. After $30 \mathrm{~min}$ of lysis buffer treatment at $4{ }^{\circ} \mathrm{C}$, insoluble material was removed by centrifugation for $30 \mathrm{~min}$ at $12000 \times \mathrm{g}$, and the protein concentration of the lysate was determined using a BCA assay. Equal amounts of protein were then separated by SDS-PAGE, transferred onto nitrocellulose membranes, and probed with the following primary antibodies: anti-p70S6K (\#2708), anti-4E-BP1(\#9644), anti-mTOR (\#2983), anti-Akt (\#92720), anti-ERK1/2 (\#4695), anti-phospho-p70S6K (Thr389, \#9234), anti-phospho-4E-BP1 (Thr37/46, \#2855), anti-phospho-mTOR (Ser2448, \#2971), anti-phospho-Akt (Ser473, \#4060), anti-phospho-ERK1/2 (Thy202/Tyr204, \#4370), anti-microtubule-associated protein 1 light chain 3 (LC3) A/B (\#4108), and anti-p62 (\#8025), antiGFP (\#2956), anti-caspase-3 (\#9662), anti-cleaved caspase-3 (\#9661), and anti-cleaved PARP (\#5625) (all from Cell Signaling Technology, Beverly, MA, USA and diluted 1:1000). After being washed with PBS, membranes were incubated with horseradish peroxidase-conjugated anti-rabbit IgG secondary antibody (1:2000, Cell Signaling Technology). Then, the membranes were washed and visualized using the ECL kit (Pierce, Rockford, IL, USA). The membranes were then reprobed for $\beta$-actin immunoreactivity using anti- $\beta$-actin antibody (1:2000, Cell Signaling Technology). Staining intensity was quantified from 3 blots derived from 3 independent experimental trials. The density of each band was quantified using ImageJ software and normalized $\beta$-actin expression. The protein levels are expressed as a ratio of the band intensity for the protein of interest to that for $\beta$-actin, which was used as a loading control.

\section{GFP-LC3 plasmid transfection and GFP-LC3 dot formation}

The GFP-LC3 fusion protein was used to visualize autophagosomes in cells. A549 cells were seeded onto coverslips placed onto a 24 -well plate at a density of $1 \times 10^{4}$ cells $/ \mathrm{mL} 24 \mathrm{~h}$ before treatment and were incubated overnight at $37^{\circ} \mathrm{C}$. The cells were transfected with $1 \mu \mathrm{g}$ GFP-LC3-expressing plasmid (Genomeditech, Shanghai, China) in each well of a 24-well plate according to the manufacturer's instructions. After $24 \mathrm{~h}$ of incubation, the medium was removed and fresh medium containing hyperoside $(2 \mathrm{mmol} / \mathrm{L})$ was added to the wells. The cells were continuously treated with hyperoside for $48 \mathrm{~h}$. At the end of treatment, cells were washed twice with PBS and fixed in $4 \%$ paraformaldehyde for $15 \mathrm{~min}$ at room temperature. After washing with PBS, coverslips were mounted on a microscope slide and observed under a fluorescence microscope.

\section{Immunofluorescence microscopy}

After fixation with $4 \%$ paraformaldehyde for $30 \mathrm{~min}$, A549 cells cultured on coverslips were permeabilized in PBS with $0.2 \%$ Triton X-100 for 5 min and incubated with 3\% BSA in PBS for $30 \mathrm{~min}$ for the immunocytochemical analysis of LC3A/B. The cells were incubated with a rabbit anti-LC3A/B (1:100; Cell Signaling Technology, Beverly, MA, USA) antibody overnight at $4{ }^{\circ} \mathrm{C}$. After extensive washes with PBS, the cells were incubated with an anti-rabbit secondary antibody conjugated with rhodamine (TRITC, 1:1000; The Jackson Labs, West Grove, PA, USA).

\section{Statistical analysis}

The data are expressed as the mean \pm SEM and were compared by one-way ANOVA followed by an LSD post hoc multiplecomparison test. $P<0.05$ was considered statistically significant.

\section{Results}

\section{Hyperoside induces autophagy in A549 cells}

At the beginning of autophagy, the cytosolic form of LC3 (LC3-I, $18 \mathrm{kDa}$ ) is converted to the phagophore and autophagosome bound form of LC3 (LC3-II, $16 \mathrm{kDa}$ ). Therefore, it is essential for formation of autophagosome and has been widely used for estimating the abundance of the autophagosome or autophagy ${ }^{[30]}$. To determine whether hyperoside induced autophagy in lung cancer cells, we first examined LC3-II levels by using Western blotting. As presented in Figure 1A, LC3II levels (compared to $\beta$-actin loading controls) increased with $0.5-2 \mathrm{mmol} / \mathrm{L}$ hyperoside treatment over $48 \mathrm{~h}$ in A549 cells in a concentration-dependent manner. The hyperosideinduced increase in LC3-II could occur at $6 \mathrm{~h}$ and could be sustained up to $48 \mathrm{~h}$ (Figure 1B). Because the autofluorescent drug MDC accumulates in mature autophagic vacuoles, such as autophagolysosomes ${ }^{[28]}$, MDC staining can be used to detect autophagic vacuoles. As shown in Figure 1C, in control cells, MDC-labeled vacuoles were partially detected. However, in $48 \mathrm{~h}$ hyperoside-treated cells, MDC-labeled fluorescent dots were markedly increased. p62 is selectively incorporated into autophagosomes through direct binding to LC3 and is efficiently degraded by autophagy ${ }^{[31]}$; thus, the total cellular expression levels of p62 inversely correlate with autophagic activity. In this study, expression levels of p62 were decreased by hyperoside treatment in a concentration-dependent manner (Figure 1D). To investigate the LC3 localization, A549 cells were transfected with a plasmid encoding GFP-LC3. After hyperoside treatment, GFP-LC3 was redistributed from a ubiquitous, diffuse pattern toward autophagosomes, which became visible as cytoplasmic dots, in A549 cells (Figure 1E). This effect was confirmed by the observation that hyperoside administration also increased the number of vesicles positive for endogenous LC3 (Figure 1F).

LC3-II can accumulate due to increased upstream autophagosome formation or impaired downstream autophagosomelysosome fusion. To distinguish between these two possibilities, we assayed LC3-II in the presence of E64d plus pepstatin A, which inhibits lysosomal proteases ${ }^{[32]}$. As shown in Figure 2A, hyperoside treatment significantly increased LC3-II levels in the presence of E64d plus pepstatin A compared to E64d plus pepstatin A alone. To confirm the hyperoside effect on autophagic flux, GFP-LC3 conversion and the appearance of cleaved GFP was detected by immunoblotting with an antiGFP antibody after hyperoside treatment (Figure 2B). These results strongly indicate that hyperoside treatment enhances 
A

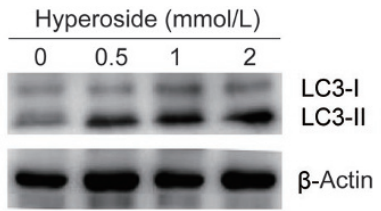

B

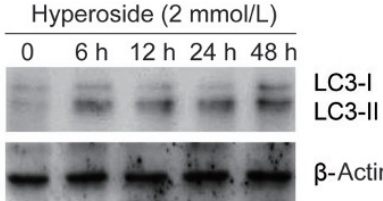

D

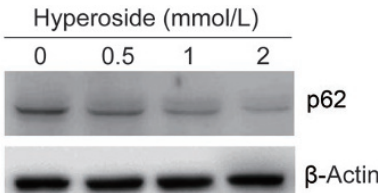
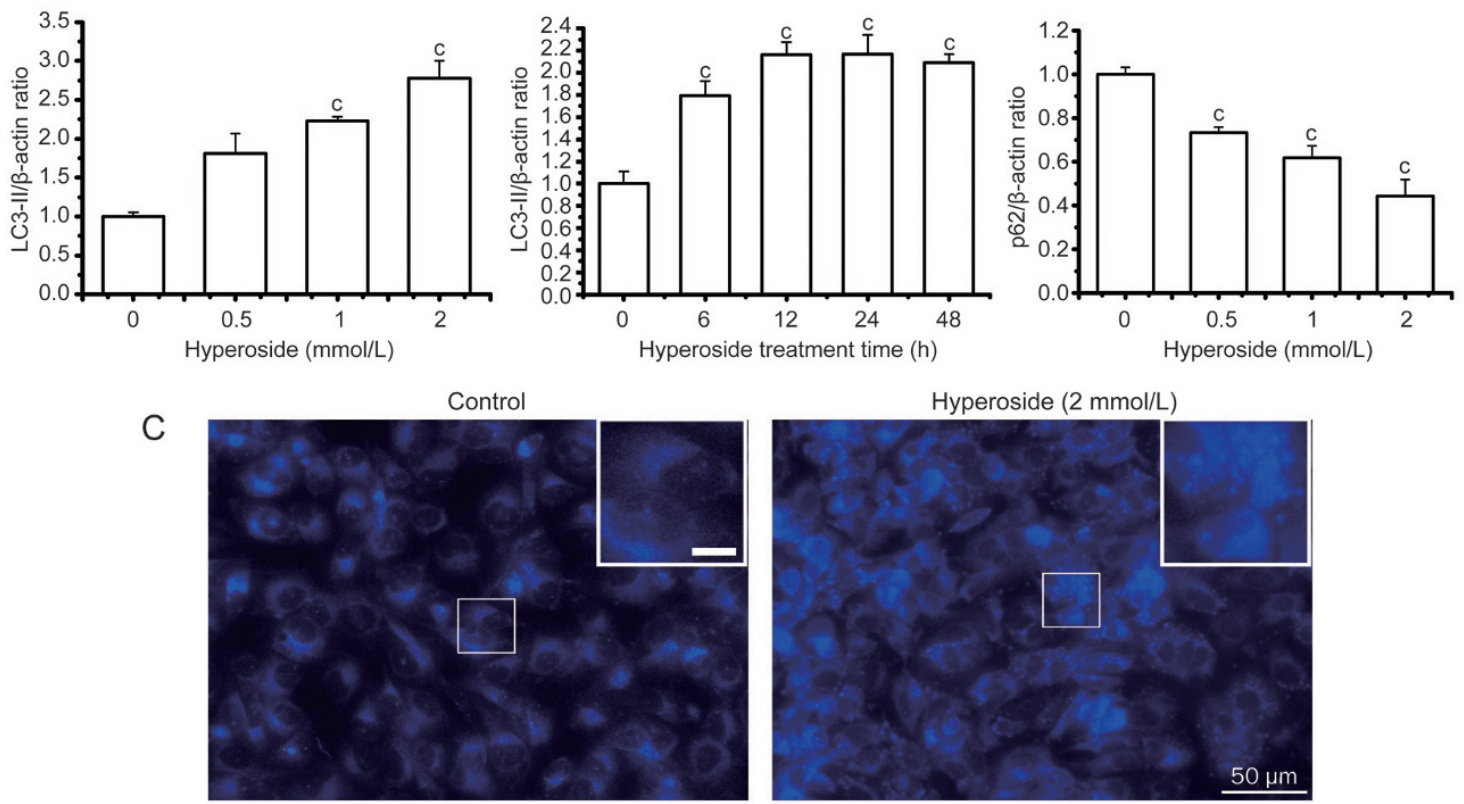

E
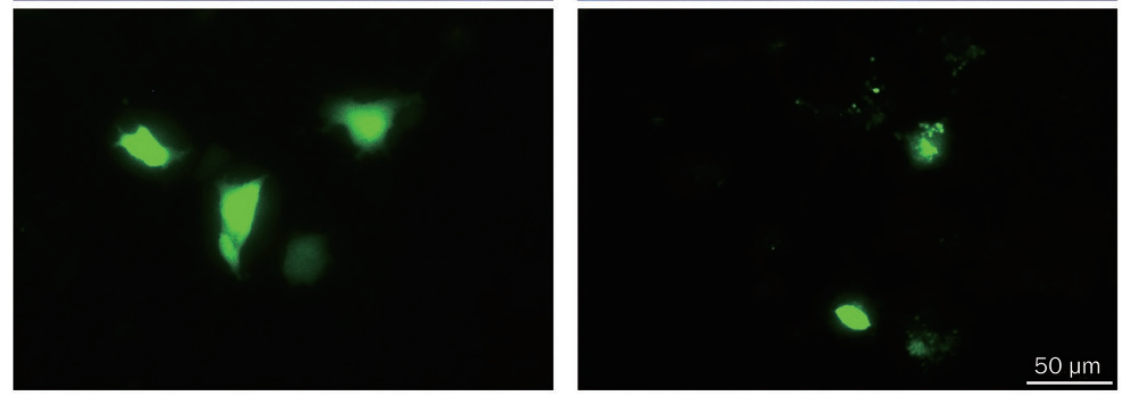

F
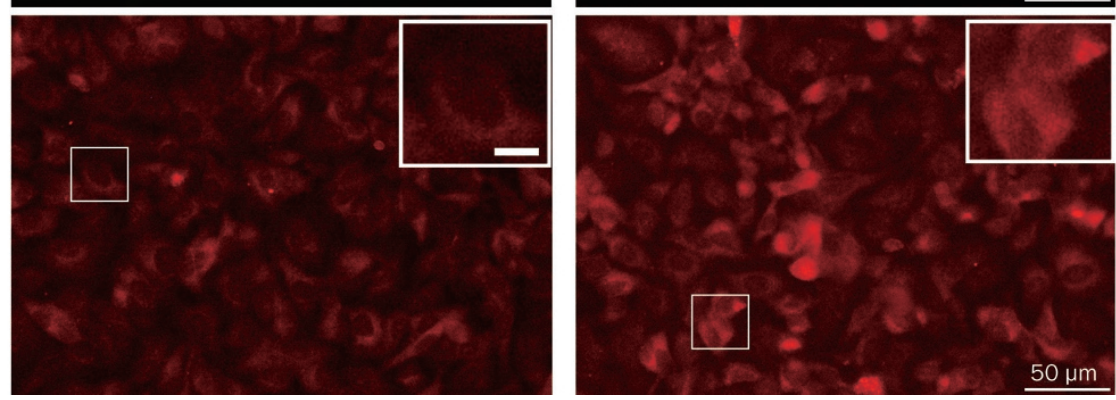

Figure 1. Hyperoside induces autophagy in human non-small cell lung cancer cell lines A549. (A) Conversions of LC3-I to LC3-II were determined by Western blotting with an antibody against LC3A/B after A549 cells were treated with various concentrations of hyperoside for $48 \mathrm{~h}$. 3 -Actin was a loading control. The bar chart shows semiquantitative analysis of LC3-II levels relative to actin using three independent experiments. (B) A549 cells treated with $2 \mathrm{mmol} / \mathrm{L}$ hyperoside for $6-48 \mathrm{~h}$ were analyzed by Western blotting with antibodies against LC3 A/B and $\beta$-actin. The bar chart shows semiquantitative analysis of LC3-II levels relative to actin using three independent experiments. (C) Monodansycadaverine (MDC) staining. A549 cells treated with hyperoside $(2 \mathrm{mmol} / \mathrm{L})$ for $48 \mathrm{~h}$ were incubated with MDC $(0.05 \mathrm{mmol} / \mathrm{L})$ for $20 \mathrm{~min}$ and observed under a fluorescence microscope. Inserts are high magnification micrographs of the boxed regions (scale bar, $10 \mu \mathrm{m}$ ). (D) A549 cells treated with various concentrations of hyperoside for $48 \mathrm{~h}$ were analyzed by immunoblotting with antibodies against p62 and $\beta$-actin. The bar chart shows semiquantitative analysis of p62 levels relative to actin using three independent experiments. (E) A549 cells transfected with GFP-LC3 expression vector for $4 \mathrm{~h}$ were subsequently treated with hyperoside ( $2 \mathrm{mmol} / \mathrm{L}$ ) for $48 \mathrm{~h}$. The GFP-LC3 dots induced by hyperoside in A549 cells were observed with a confocal microscope. (F) A549 cells treated with $2 \mathrm{mmol} / \mathrm{L}$ hyperoside for $48 \mathrm{~h}$ were stained with antibodies against LC3A/B. They were analyzed with confocal microscopy. Inserts are high magnification micrographs of the boxed regions (scale bar, $10 \mu \mathrm{m}$ ). The data are expressed as the mean \pm SEM of 3 independent experiments. ${ }^{\mathrm{c}} P<0.01$ compared with the control group. 
autophagic flux.

Hyperoside inhibits the Akt/mTOR/p70S6K signaling pathway and activates the ERK1/2 signaling pathway in A549 cells

The PI3K/Akt/mTOR signaling pathway, which is associated with tumorigenesis and often activated in numerous types of tumors, plays a critical role in autophagy and cell proliferation. The inhibition of this signaling pathway is linked to the triggering of autophagy ${ }^{[33]}$. Thus, we sought to test whether hyperoside could induce autophagy by inhibition of this pathway using Western blotting. After a $24 \mathrm{~h}$ treatment with hyperoside, there was a significant decrease in the levels of phosphorylated p70S6 kinase (Figure 3A) and 4E-BP1 (Figure 3B) in a concentration-dependent manner compared with total normal levels in A549 cells. To further ascertain the requirement for mTOR pathway inhibition in hyperoside-induced autophagy, we used a phospho-specific mTOR antibody (Ser2448), which has been shown to be important in the control of mTOR. As expected, hyperoside treatment also decreased the level of phosphorylated mTOR and mTOR in A549 cells (Figure 3C). To further investigate the upstream inhibition of mTOR by hyperoside, we used an antibody specific for phosphorylated serine 473 , which measures both Akt/mTOR and mTORC2 activity. As shown in Figure 3D, treatment with hyperoside caused marked decreases in phosphorylated Akt in a concentration-dependent manner. In addition, increased activity of ERK1/2 has been reported to be required for induction of autophagy ${ }^{[17]}$. Therefore, we investigated whether hyperoside increases the level of phosphorylated ERK1/2, a key regulator of autophagy downstream of Akt. As shown in Figure 3E, treatment with hyperoside increased the level of phosphorylated ERK1/2. The inhibitory effects of hyperoside on phospho-mTOR and phospho-p70S6K were initially detected $6 \mathrm{~h}$ after the addition of hyperoside, reaching a maximal level after $24 \mathrm{~h}$ (Figure 3F).

\section{Hyperoside-induced autophagy is dependent on the PI3K/Akt/ mTOR pathway}

Our above findings that hyperoside decreased the levels of major proteins in the Akt/mTOR pathway prompted us to investigate whether hyperoside-induced autophagy is activated through this pathway. It has been reported that insulin not only activates the PI3K/Akt/mTOR signaling pathway but also suppresses autophagy ${ }^{[3,35]}$. As shown in Figure 4A, insulin treatment for 30 min significantly increased the level of phospho-Akt (Ser473) whereas the phosphorylation of Akt was almost completely abolished by hyperoside $(2 \mathrm{mmol} / \mathrm{L})$ pretreatment. The LC3-II/actin ratio was suppressed by insulin; however, this effect of insulin was reduced by hyperoside pretreatment (Figure 4B). Furthermore, the hyperoside and Akt inhibitor triciribine did not have additive effects on the levels of LC3-II/actin ratio compared to the single treatment of hyperoside or triciribine (Figure 4C and 4D). To further clarify whether hyperoside facilitates autophagy through ERK1/2 signaling, A549 cells were treated with the mitogenactivated protein kinase kinase 1/2 (MEK1/2) inhibitor U0126 for $4 \mathrm{~h}$ followed by treatment with or without hyperoside for $24 \mathrm{~h}$. The results showed that U0126 significantly but mildly reversed the levels of the LC3-II/actin ratio (Figure 4F). The failure of U1026 to completely reverse the hyperoside effect can be explained by the autophagy induction through Akt/ mTOR signaling.

Because hyperoside-induced autophagy is dependent on mTOR inhibition, we looked at the effects of hyperoside on autophagy in the presence of rapamycin. We hypothesized that combination treatment of hyperoside with rapamycin would not have additive effects on autophagy. However, the results showed that the combination treatment of hyperoside with rapamycin showed an additive effect on the enhancement of LC3-II/actin ratio compared to the single treatment with hyperoside or rapamycin (Figure 5A). The results of
A

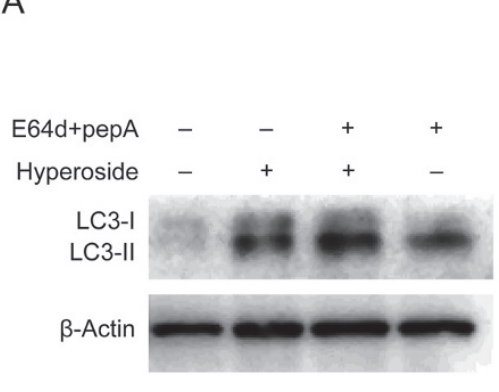

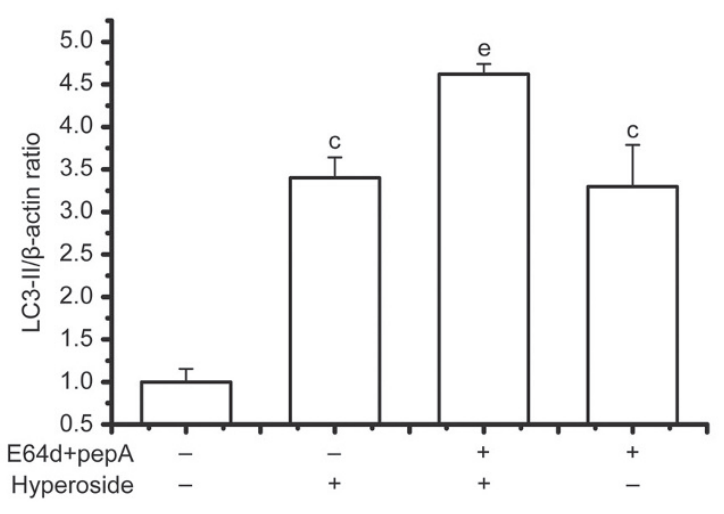

B

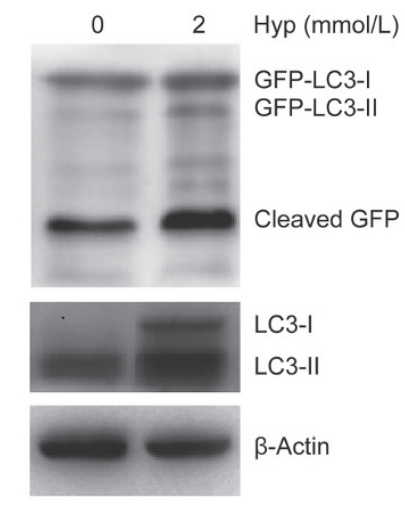

Figure 2. Hyperoside induced autophagic flux in a human non-small cell lung cancer cell line. (A) A549 cells treated with hyperoside (2 mmol/L) with or without E64d $(10 \mu \mathrm{g} / \mathrm{mL})$ and pepstatin $A(10 \mu \mathrm{g} / \mathrm{mL})$ were analyzed by immunoblotting with antibodies against LC3A/B and $\beta$-actin. The bar chart shows semiquantitative analysis of LC3 levels relative to $\beta$-actin using three independent experiments. (B) A549 cells transfected with GFPLC3 expression vector for $24 \mathrm{~h}$ were treated with $(2 \mathrm{mmol} / \mathrm{L})$ hyperoside for $48 \mathrm{~h}$. Conversions of GFP-LC3 and endogenous LC3 were determined by Western blotting. $\beta$-Actin was a loading control. The data are expressed as the mean \pm SEM of 3 independent experiments. ${ }^{\circ} P<0.01$ compared with the control group. ${ }^{e} P<0.05$ compared with the E64d and pepstatin A group. 
A
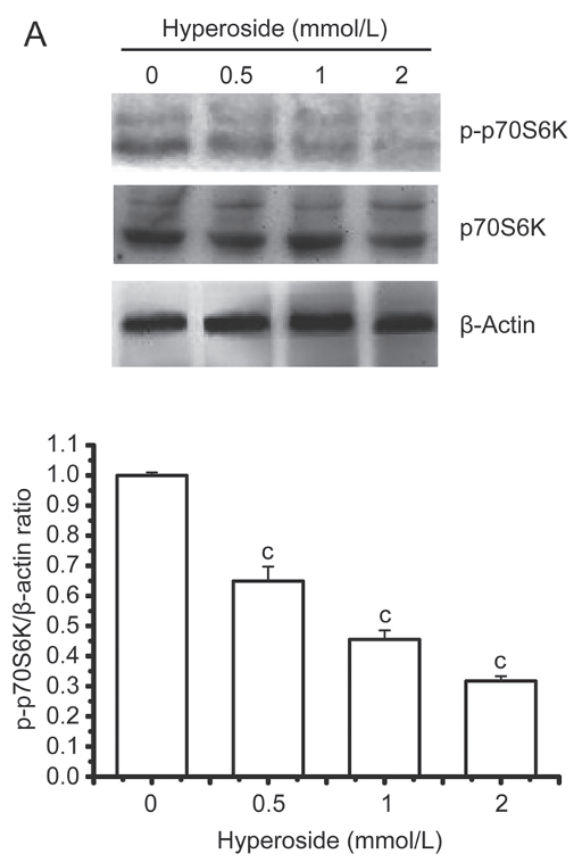

D
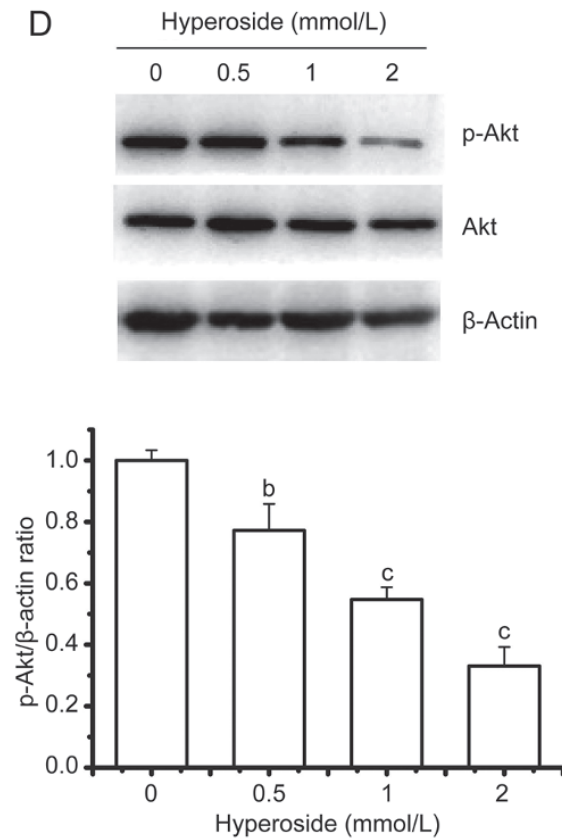

B

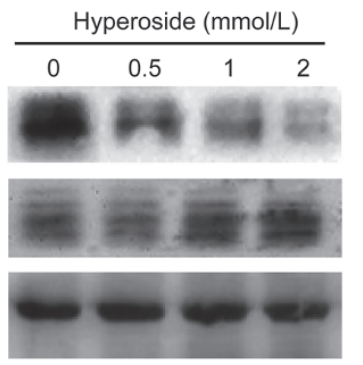

s.

4E-BP1

$\beta$-Actin
C

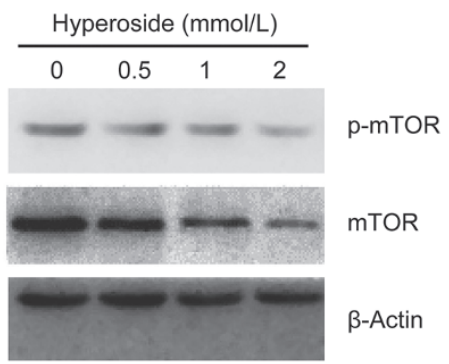

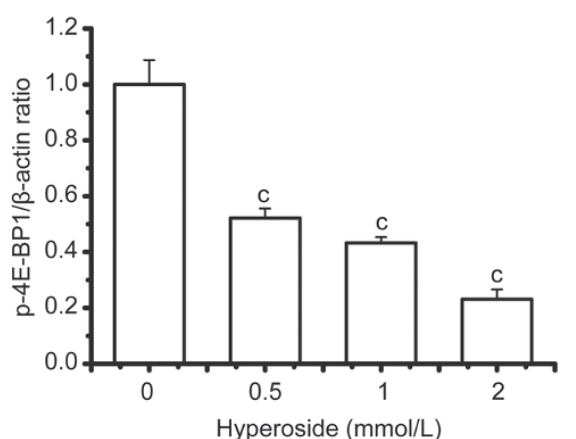

E

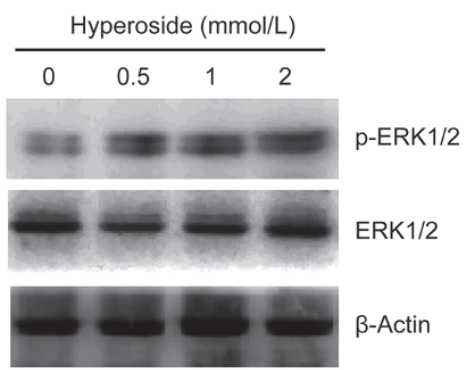

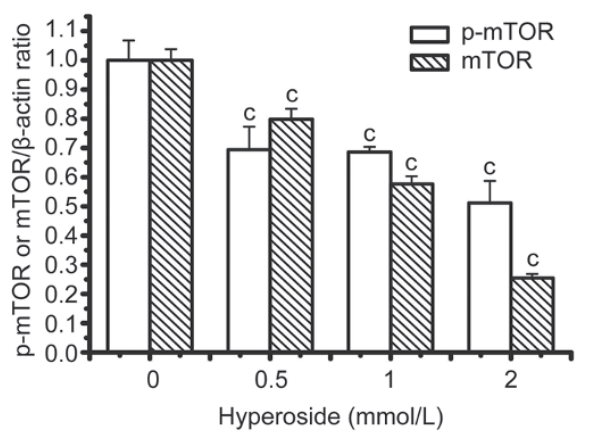

F

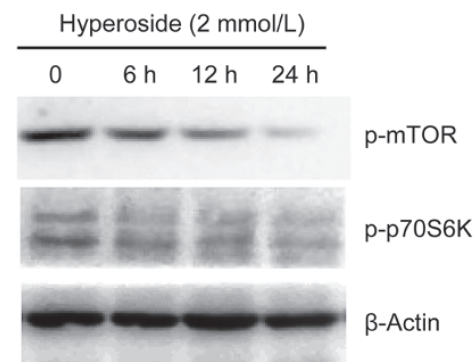

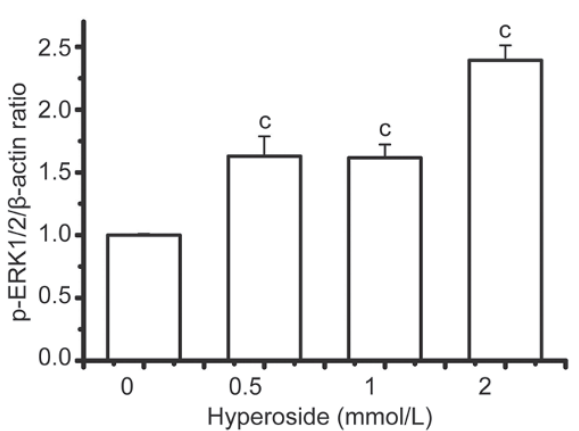

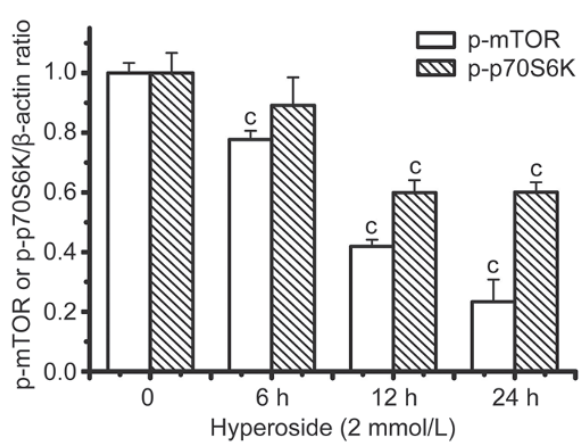

Figure 3. Hyperoside inhibits the Akt/mTOR/p70S6 signaling pathway and activates ERK1/2 signaling in A549 cells. A549 cells treated with hyperoside $(0.5,1$, and $2 \mathrm{mmol} / \mathrm{L})$ for $24 \mathrm{~h}$ were analyzed by Western blotting against phospho-p70S6K (Thr389) and total p70S6K (A), phospho-4EBP1 (Thr37/46) and total 4E-BP1 (B), phospho-mTOR (Ser2448) and total mTOR (C), phospho-Akt (Ser473) and total Akt (D), and phospho-ERK1/2 and total ERK1/2 (E). $\beta$-Actin was a loading control. Group data showing normalized phosphorylated or total kinases to $\beta$-actin were determined in each group of three experiments. (F) A549 cells treated with $2 \mathrm{mmol} / \mathrm{L}$ hyperoside for 6,12 , or $24 \mathrm{~h}$ were analyzed by immunoblotting for levels of phosphomTOR and phospho-p70S6K. $\beta$-Actin was a loading control. The data are expressed as the mean \pm SEM of 3 independent experiments. ${ }^{b} P<0.05$, ${ }^{\mathrm{c}} P<0.01$ compared with the control group.

MDC staining confirmed this additive effect (Figure 5B).

Role of autophagy in hyperoside-induced A549 cell death

Autophagy plays a critical role in regulation of survival or cell death ${ }^{[36]}$. Therefore, we decided to investigate whether hyperoside-induced autophagy rescues or induces cell death. A549 cells were treated with hyperoside $(0.1,0.5,1$, and 2 $\mathrm{mmol} / \mathrm{L}$ ) for $24 \mathrm{~h}$ or $48 \mathrm{~h}$, and cell viability was determined using the MTT assay. Hyperoside treatment induced a significant decrease in cell viability in a time- and concentration- 

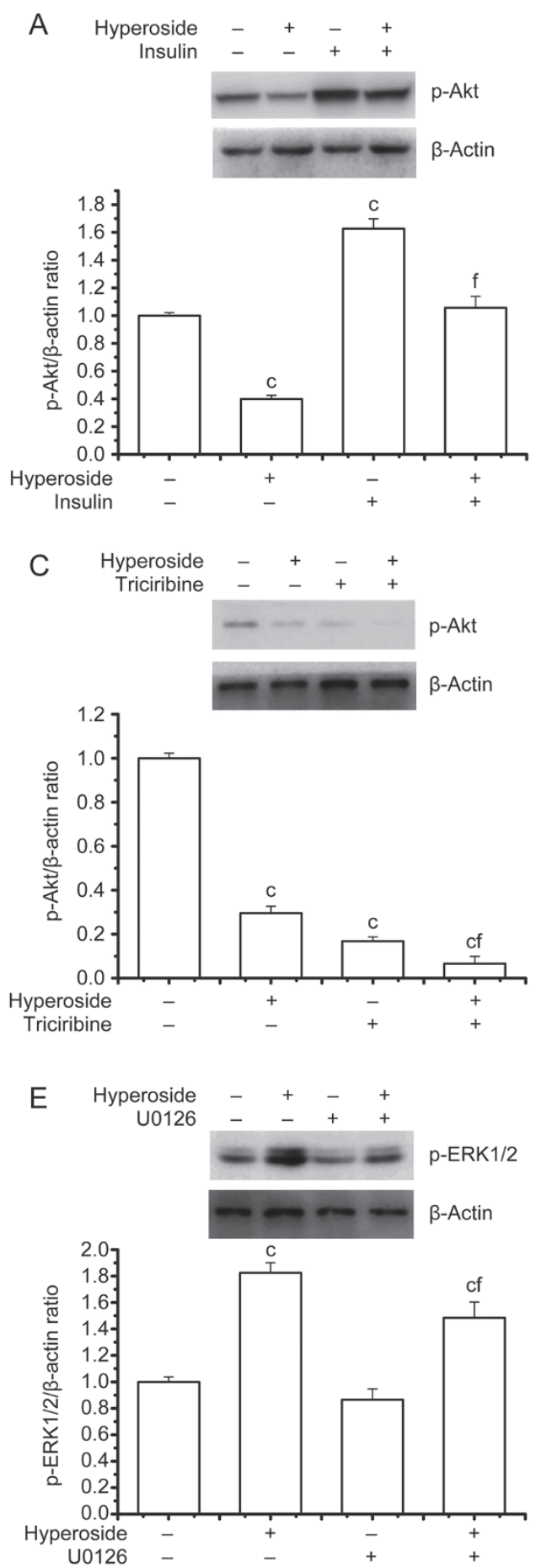
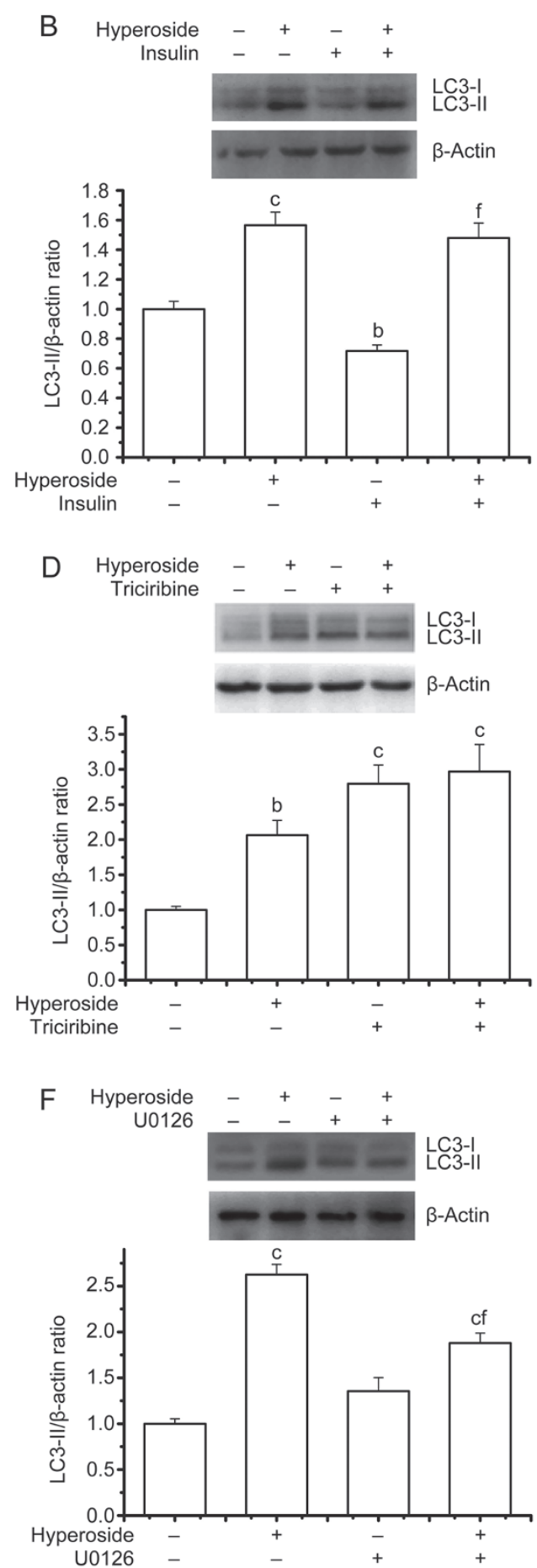

Figure 4. Hyperoside-induced autophagy is dependent on the PI3K/Akt/mTOR pathway. (A and B) A549 cells treated with hyperoside (2 mmol/L) for $4 \mathrm{~h}$ followed by treatment with or without $200 \mathrm{nmol} / \mathrm{L}$ insulin for $30 \mathrm{~min}$ were analyzed by Western blotting against phospho-Akt (A) or LC3A/B (B). Group data showing normalized phosphorylated Akt or LC3-II to $\beta$-actin were determined in each group of three experiments. The data are expressed as the mean \pm SEM. ${ }^{c} P<0.01$ compared with the control group. ${ }^{f} P<0.01$ compared with insulin group. (C and D) A549 cells treated with hyperoside $(2$ $\mathrm{mmol} / \mathrm{L}$ ), $30 \mu \mathrm{mol} / \mathrm{L}$ triciribine, or hyperoside $(2 \mathrm{mmol} / \mathrm{L}$ ) with $30 \mu \mathrm{mol} / \mathrm{L}$ triciribine for $12 \mathrm{~h}$ were analyzed by immunoblotting against phospho-Akt (C) or LC3A/B (D). Group data showing normalized phosphorylated Akt or LC3-II to $\beta$-actin were determined in each group of three experiments. The data are expressed as the mean \pm SEM. ${ }^{b} P<0.05,{ }^{c} P<0.01$ compared with the control group. ${ }^{f} P<0.01$ compared with triciribine group. (E and $F$ ) A549 cells treated with $2 \mathrm{mmol} / \mathrm{L}$ hyperoside with or without $20 \mu \mathrm{mol} / \mathrm{L}$ U0126 for $12 \mathrm{~h}$ were analyzed by immunoblotting using antibodies against phospho-ERK (E) or LC3A/B (F). Group data showing normalized phosphorylated ERK or LC3A/B to $\beta$-actin were determined in each group of three experiments. The data are expressed as the mean \pm SEM. ${ }^{\mathrm{C}} P<0.01$ compared with the control group. ${ }^{\mathrm{f}} P<0.01$ compared with hyperoside group. 
A
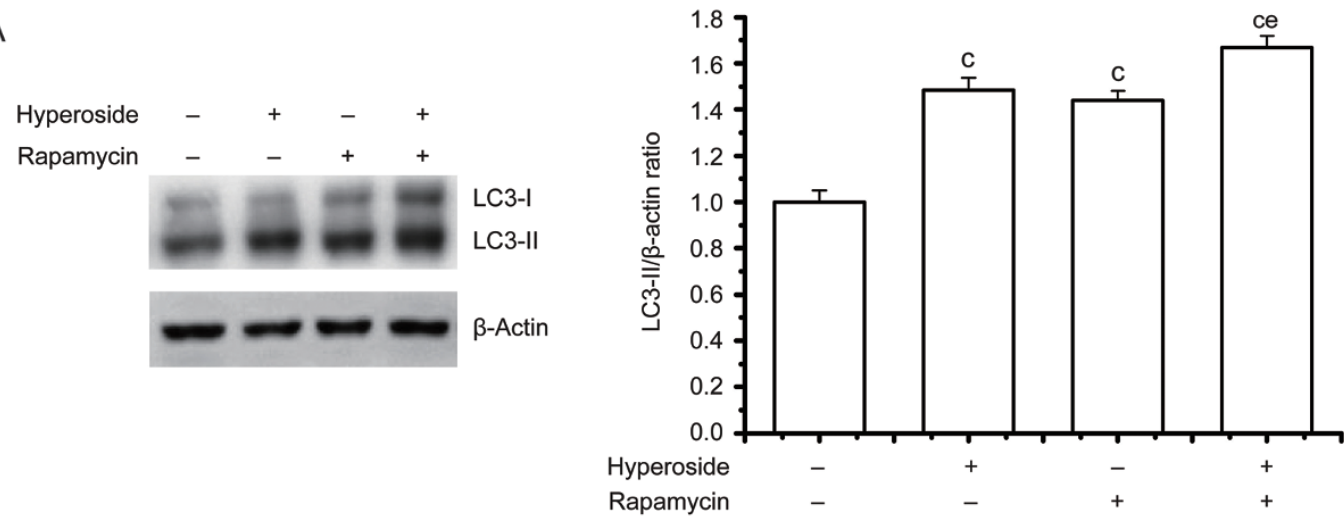

B
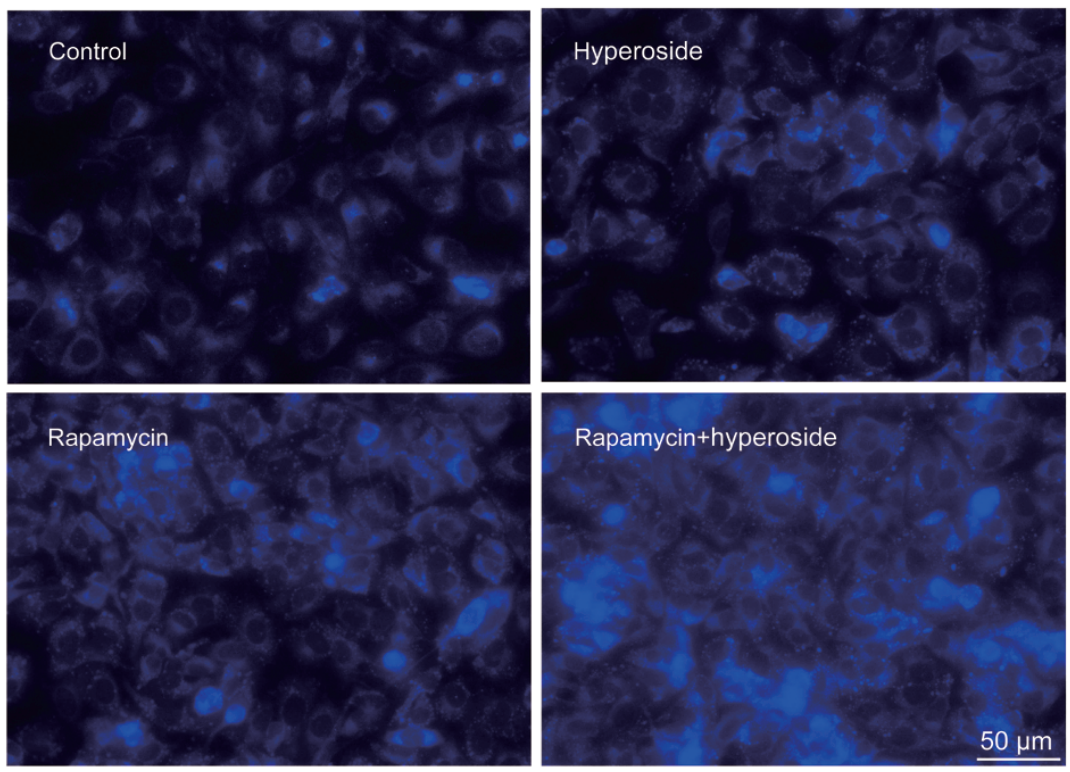

Figure 5. Rapamycin treatment with hyperoside shows an enhancement of autophagy. (A) A549 cells treated with rapamycin (1 $\mu$ mol/L) with or without $2 \mathrm{mmol} / \mathrm{L}$ hyperoside for $48 \mathrm{~h}$ were analyzed by Western blotting with antibodies against LC3A/B and $\beta$-actin. The bar chart shows the LC3-II/actin ratio using three independent experiments. The data are expressed as the mean \pm SEM of 3 independent experiments. ${ }^{c} P<0.01$ compared with the control group. ${ }^{e} P<0.05$ compared with the single treatment of hyperoside. (B) A549 cells treated with hyperoside (2 mmol/L) with or without rapamycin (1 $\mu \mathrm{mol} / \mathrm{L})$ for $48 \mathrm{~h}$ were incubated with MDC $(0.05 \mathrm{mmol} / \mathrm{L})$ for $20 \mathrm{~min}$ and observed under a fluorescence microscope.

dependent manner (Figure 6A). Additionally, the BrdU incorporation assay was used to examine the effect of hyperoside on the proliferation of A549 cells. Continuous treatment of A549 cells with hyperoside for $48 \mathrm{~h}$ significantly inhibited the cell proliferation in a concentration-dependent manner (Figure 6B). Furthermore, we investigated the effects of hyperoside on cell viability in the presence of an autophagy inhibitor in A549 cells. The autophagy inhibitor 3-MA is commonly used to define the role of autophagy under various physiological conditions $^{[37]}$. As shown in Figure 6C and D, 3-MA, a specific inhibitor of the early-stage autophagic process ${ }^{[38]}$, suppressed the expression of the LC3 protein and hyperoside-induced decrease in cell viability in A549 cells. These data suggest that hyperoside-induced autophagy is not protective in A549 cells and leads to cell death.
Inhibition of autophagy reduced hyperoside-induced apoptotic cell death

Autophagy and apoptosis may act independently in parallel pathways or may influence one another ${ }^{[5]}$. Autophagy may cooperate with apoptosis to promote cell death ${ }^{[39]}$. To determine if apoptosis occurs in hyperoside-induced A549 cell death, we examined the activity of caspase- 3 and cleaved PARP proteins, the biochemical hallmarks of an apoptotic event. Treatment with various concentrations of hyperoside $(0.5,1$, and $2 \mathrm{mmol} / \mathrm{L})$ markedly increased levels of cleaved caspase-3 (Figure 7A) and cleaved PARP (Figure 7B) and decreased the levels of full-length caspase-3 in A549 cells in a concentration-dependent manner (Figure 7A). These data indicated that hyperoside induced apoptosis in lung cancer cells. 
A
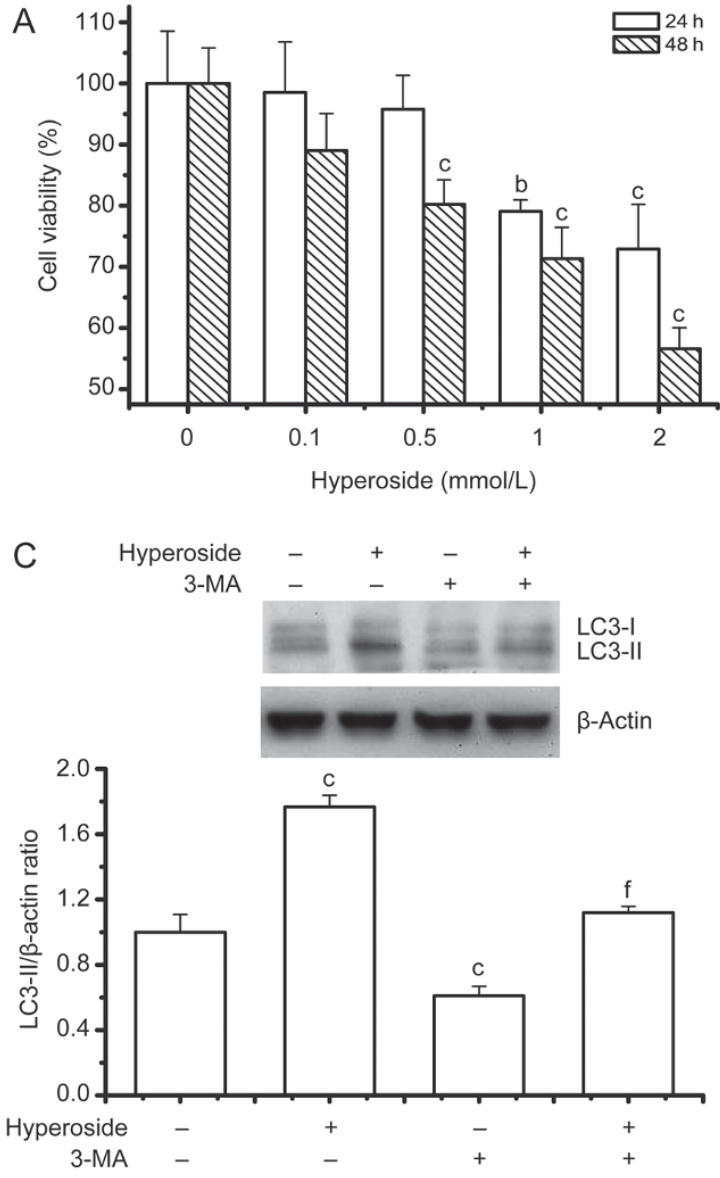

B

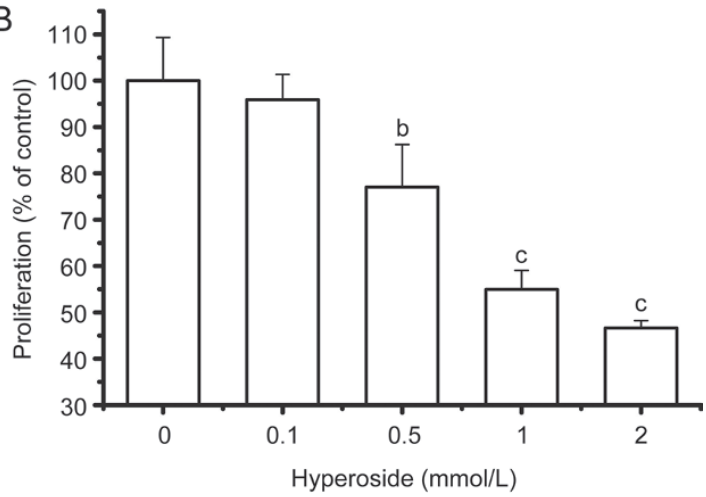

D

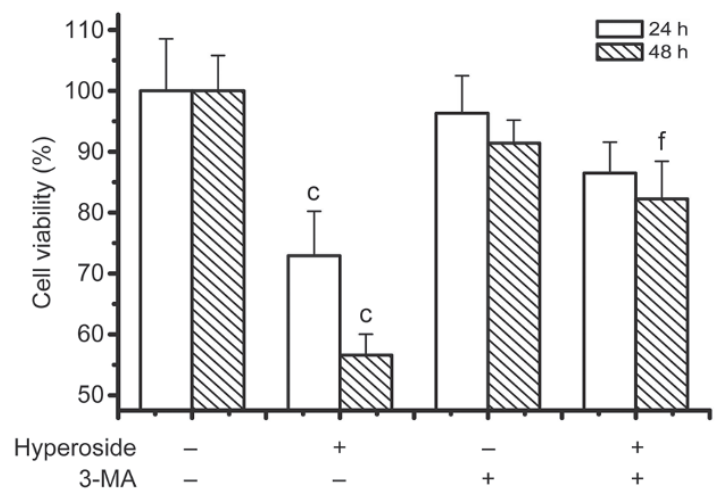

Figure 6. Autophagy is involved in hyperoside-induced A549 cell death. (A) A549 cells $\left(5 \times 10^{3}\right.$ cells/well in 96 -well plate) were treated with different concentrations of hyperoside $(0.1,0.5,1$, and $2 \mathrm{mmol} / \mathrm{L})$ for $24 \mathrm{~h}$ or $48 \mathrm{~h}$. Cell viability was analyzed by the MTT assay. (B) After A549 cells $\left(5 \times 10^{3}\right.$ cells/well in 96-well plate) were treated with different concentrations of hyperoside $(0.1,0.5,1$, and $2 \mathrm{mmol} / \mathrm{L})$ for $48 \mathrm{~h}$, cell proliferation was measured using the BrdU incorporation assay. ( $C$ and D) A549 cells were pretreated with $2.5 \mathrm{mmol} / \mathrm{L}$ 3-MA for $1 \mathrm{~h}$ before the addition of $2 \mathrm{mmol} / \mathrm{L}$ hyperoside for an additional incubation of 24 or $48 \mathrm{~h}$. Cellular proteins of the $48 \mathrm{~h}$ treatment sample were lysed and subjected to Western blot analysis with an antiLC3A/B antibody. The bar chart showed LC3-II/ $\beta$-actin ratio using three independent experiments (C). Cell viability was analyzed by the MTT assay (D). The data are expressed as the mean \pm SEM of 3 independent experiments. ${ }^{b} P<0.05,{ }^{c} P<0.01$ compared with the control group. ${ }^{f} P<0.01$ compared with the single treatment with hyperoside $(2 \mathrm{mmol} / \mathrm{L})$.

To test whether hyperoside-induced apoptosis is dependent on autophagy, we investigated the apoptotic effect of inhibition of autophagy by 3-MA after hyperoside exposure. A549 cells were treated with hyperoside $(2 \mathrm{mmol} / \mathrm{L})$ in the presence or absence of 3-MA ( $2 \mathrm{mmol} / \mathrm{L})$ for $48 \mathrm{~h}$. 3-MA pretreatment markedly attenuated the hyperoside-induced up-regulation of cleaved caspase-3 and cleaved PARP (Figure 7C). Pretreatment with 3-MA remarkably attenuated the formation of autophagic vacuoles in the presence of hyperoside (Figure 7D), suggesting that hyperoside-induced apoptosis of A549 cells is at least partly dependent on autophagy.

\section{Hyperoside does not affect human bronchial epithelial cells}

To evaluate if hyperoside has any effect on non-tumor cells, the bronchial epithelial cell line BEAS-2B was used in further experiments. As shown in Figure 8A, hyperoside did not cause a significant increase in LC3-II protein levels in BEAS-
$2 \mathrm{~B}$ cells. In comparison, the same concentration of hyperoside tested under comparable experimental conditions resulted in a 2.8-fold increase in LC3-II protein levels in the lung cancer cell line A549. The results of MDC staining revealed that hyperoside treatment did not induce a significant increase in the formation of autophagic vacuoles in BEAS-2B cells (Figure 8B).

\section{Discussion}

Currently, it has been reported that hyperoside exhibits anticancer properties by inhibiting cell proliferation, inducing apoptosis, decreasing angiogenesis, and causing cell cycle arrest in several cancer cell lines ${ }^{[40]}$. However, whether hyperoside induces autophagy and its molecular mechanisms remain unknown. The results of this study showed that hyperoside induced autophagy accompanied by apoptosis in A549 cells. Regarding signal pathways, hyperoside inhibited the Akt/mTOR/p70S6K and activated the ERK1/2 pathways, 
A
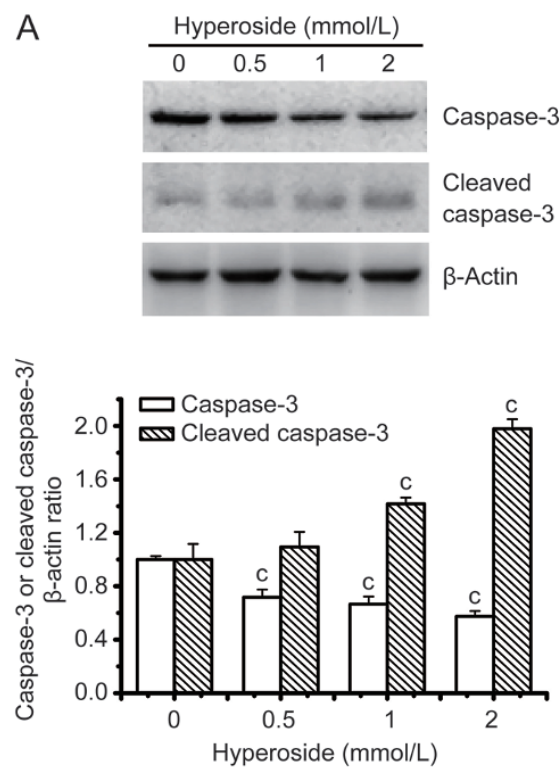

B

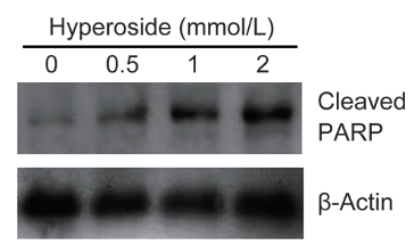

C
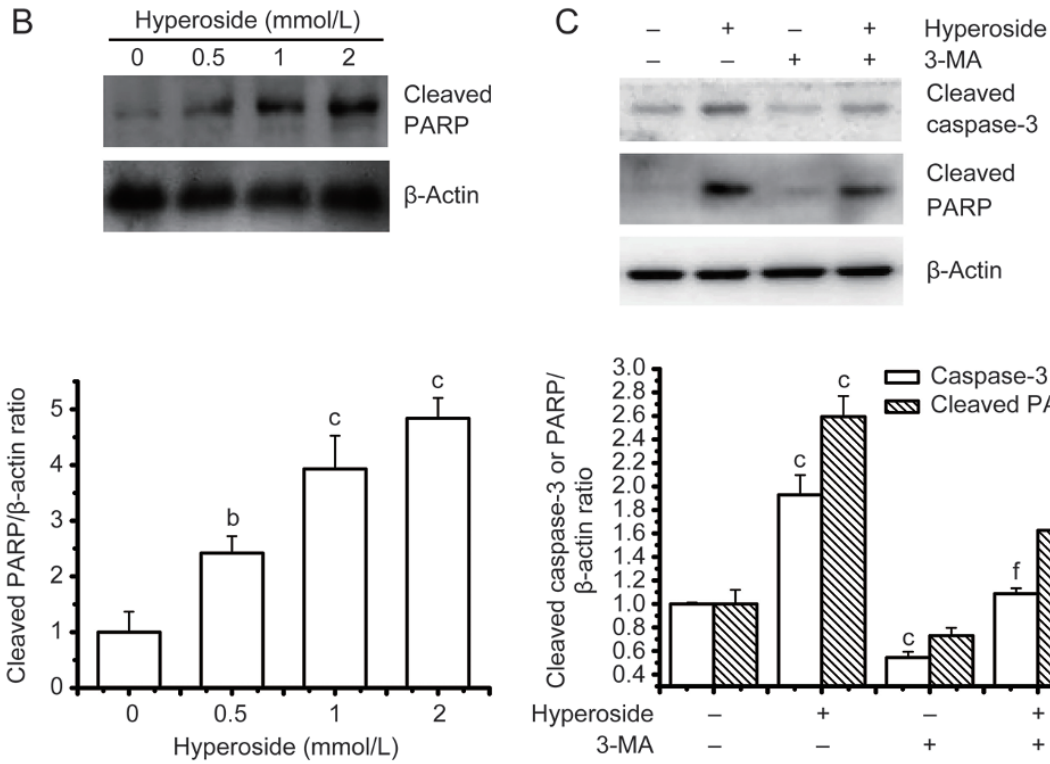

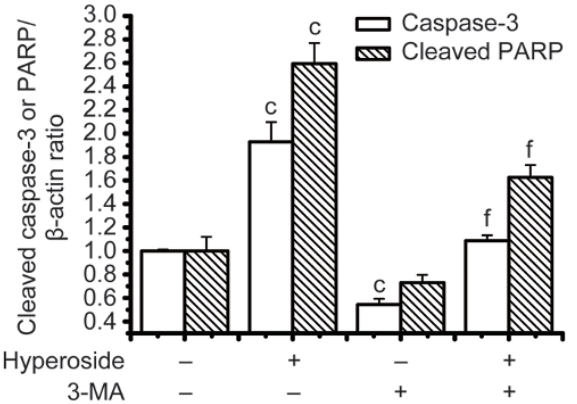

D
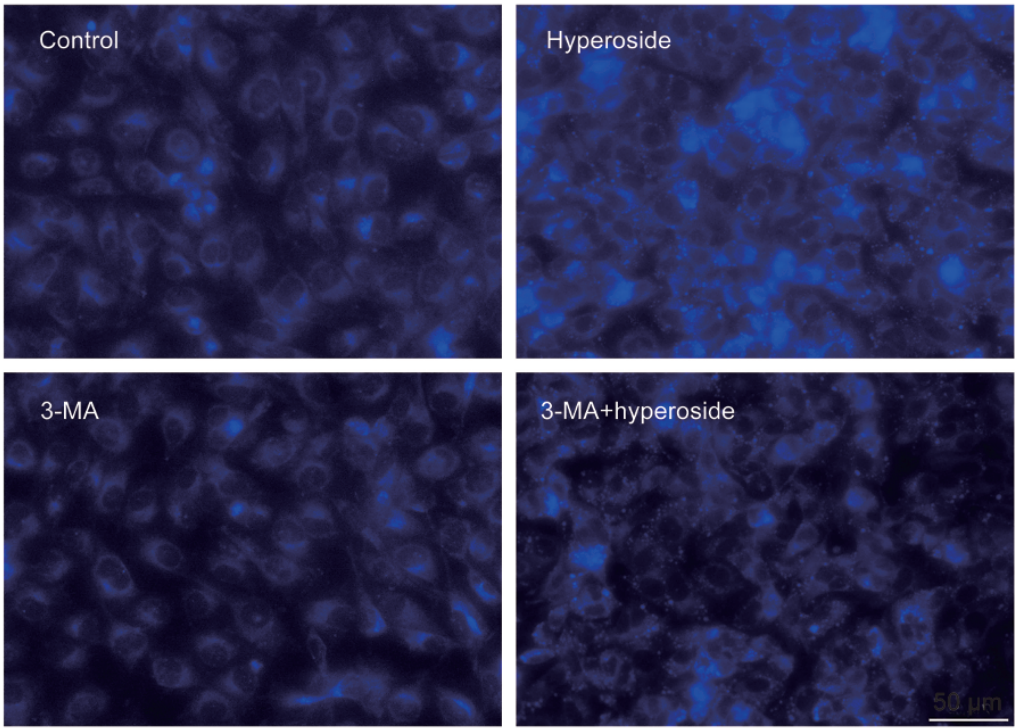

Figure 7. Inhibition of autophagy reduced hyperoside-induced apoptotic cell death. (A) A549 cells were treated with hyperoside (0.5, 1 or 2 mmol/L) for $48 \mathrm{~h}$ and analyzed with immunoblotting for levels of caspase-3 and cleaved caspase-3. The bar chart shows semiquantitative analysis of caspase-3 or cleaved caspase- 3 to $\beta$-actin using three independent experiments. (B) A549 cells were treated with hyperoside $(0.5,1$ or $2 \mathrm{mmol} / \mathrm{L})$ for $48 \mathrm{~h}$ and analyzed with immunoblotting for cleaved PARP. The bar chart shows semiquantitative analysis of cleaved PARP. (C) A549 cells were treated with hyperoside ( $2 \mathrm{mmol} / \mathrm{L}$ ) with or without 3-MA ( $2 \mathrm{mmol} / \mathrm{L})$ for $48 \mathrm{~h}$ and analyzed with immunoblotting for cleaved caspase-3 and cleaved PARP. The bar chart shows cleaved caspase- 3 or cleaved PARP/ $\beta$-actin ratio. The data are expressed as the mean \pm SEM of 3 independent experiments. ${ }^{b} P<0.05,{ }^{c} P<0.01$ compared with the control group. ${ }^{f} P<0.01$ compared with the single treatment with hyperoside ( 2 mmol/L). (D) A549 cells treated with hyperoside ( $2 \mathrm{mmol} / \mathrm{L})$ with or without 3-MA ( $2 \mathrm{mmol} / \mathrm{L})$ for $48 \mathrm{~h}$ were incubated with MDC $(0.05 \mathrm{mmol} / \mathrm{L})$ for $20 \mathrm{~min}$ and observed under a fluorescence microscope.

resulting in autophagy. We also found that inhibition of autophagy by specific inhibitors (3-MA) increased cell viability and significantly decreased apoptosis in A549 cells. The results strongly indicate that autophagy is important in anticancer functions of hyperoside.

Autophagy is considered an alternative therapeutic approach in cancer cells ${ }^{[41]}$. Autophagy involves the formation of autophagosomes that assemble around and encapsulate damaged organelles or cellular debris and then fuse with lysosomes to degrade their contents ${ }^{[42]}$. The presence of LC3 in autophagosomes and the conversion of LC3-I to LC3II are known indicators of autophagy ${ }^{[43]}$. Detection of LC3 using Western blotting showed that in A549 lung cancer cells, hyperoside treatment increased the conversion of LC3-I to 
A

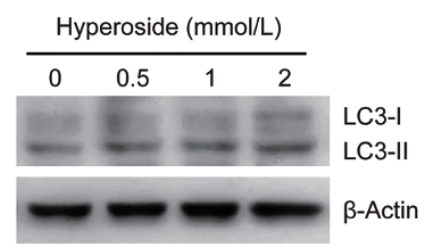

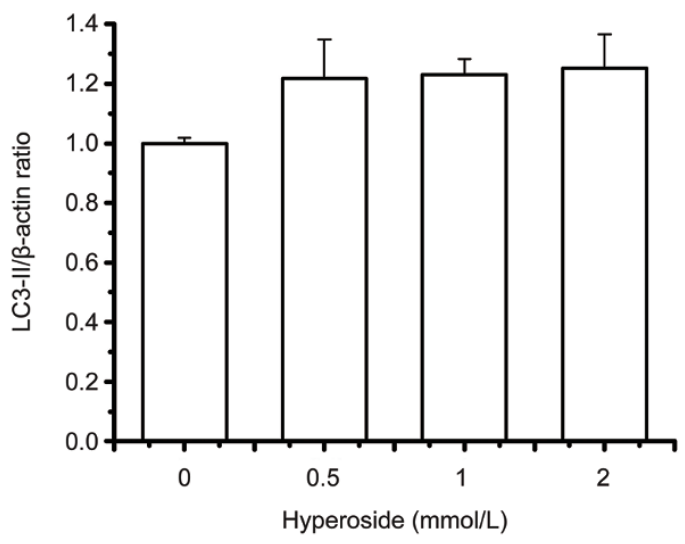

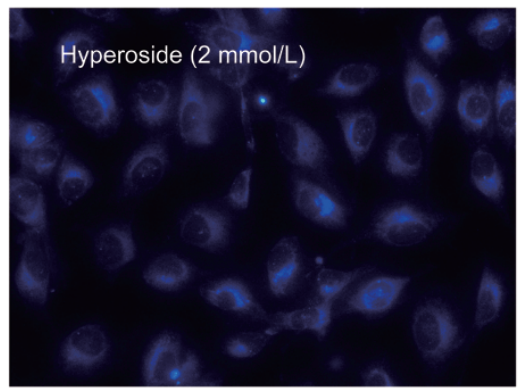

Figure 8. Effect of hyperoside on autophagy in human bronchial epithelial cells BEAS-2B. (A) Conversions of LC3-I to LC3-II were determined by Western blotting with an antibody against LC3A/B after BEAS-2B cells were treated with various concentrations of hyperoside for $48 \mathrm{~h}$. $\beta$-Actin was a loading control. The bar chart shows semiquantitative analysis of LC3-II levels relative to $\beta$-actin using three independent experiments. The data are expressed as the mean \pm SEM of 3 independent experiments. (B) BEAS-2B cells treated with hyperoside $(2 \mathrm{mmol} / \mathrm{L})$ for $48 \mathrm{~h}$ were incubated with $\mathrm{MDC}(0.05 \mathrm{mmol} / \mathrm{L})$ for 20 min and observed under a fluorescence microscope.

II in a dose- and time-dependent manner. LC3-II binds to p62/SQSTM1, which is involved in trafficking proteins to the proteasome and facilitates the autophagic degradation of ubiquitinated protein aggregates ${ }^{[31]}$. p62/SQSTM1 is normally degraded with autophagosomes and accumulates when autophagy is impaired ${ }^{[6]}$. In this study, expression levels of p62 were also decreased by hyperoside treatment. Autophagic flux implies a balance between autophagosome formation and autophagic degradation. Either increased autophagosome formation in the early stage or defective degradation in the late stage can lead to accumulation of autophagic vacuoles. Lysosomal degradation can be prevented through the use of protease inhibitors such as E64d plus pepstatin A.

In our study, hyperoside-induced LC3-II accumulation could be a result of either LC3-I to LC3-II conversion or defects in LC3-II degradation. To distinguish between these two possibilities, we assayed LC3-II in the presence of E64d plus pepstatin A. The results showed that hyperoside significantly increased LC3-II levels in the presence of E64d plus pepstatin A compared to E64d plus pepstatin A alone in A549 cells. This implies that the rate of autophagosome formation is much higher than its turnover by lysosomes. According to these results, hyperoside elicits an extremely imbalanced autophagic flux, leading to a cytotoxic effect on lung cancer cells. The impact of hyperoside on healthy tissue was evaluated by use of the bronchial epithelial cell line BEAS-2B. In contrast to lung cancer cells, hyperoside failed to induce significant autophagy in BEAS-2B cells.

Because activation of PI3K/Akt occurs in 90\% of NSCLC cell lines, it has become an important target for the development of anti-cancer drugs. Several anti-cancer agents are known to inhibit the PI3K/Akt/mTOR/p70S6K pathway, resulting in induction of autophagy in tumor cell lines ${ }^{[17]}$. In this study, we found that hyperoside treatment significantly decreased the expression levels of phospho-Akt (Ser473), phospho-mTOR, phospho-p70S6K (Thr389) and phospho-4E-BP1 (Thr37/46) in A549 cells. Our results show that hyperoside treatment inhibited the components of the Akt/mTOR/p70S6K pathway. The intriguing finding in this study is that hyperoside decreases mTOR protein level in A549 cells. Hyperoside might induce mTOR protein degradation. A recent study has shown that some proteins, such as mTOR and p70S6K, can be regulated through facilitating proteasome-mediated protein degradation $^{[44]}$. More studies will be needed to fully elucidate the mechanisms by which hyperoside decreases the mTOR protein level.

Next, we used insulin to further clarify the correlation between insulin-mediated activation of the PI3K/Akt/ 
mTOR pathway and hyperoside-induced autophagy. Insulin upregulates PI3K and its downstream targets, including Akt and mTOR, resulting in the inactivation of autophagy ${ }^{[34]}$. Our results provided evidence that insulin activated this signaling pathway, leading to autophagy suppression, and the effect of insulin was abolished by hyperoside addition. mTOR serves as a central regulator of autophagy and forms two distinct signaling complexes, known as mTORC1 and mTORC2 ${ }^{[13]}$. A number of upstream signaling pathways involved in autophagy regulation converge on $\mathrm{mTOR}$ and include the class I PI3K/Akt pathway ${ }^{[45]}$. Suppression of mTOR triggers the autophagic cascade and inhibits cell proliferation. Rapamycin is a naturally occurring mTOR inhibitor. Furthermore, the ratio of LC3-II/actin was enhanced by hyperoside cotreatment with rapamycin compared with that of hyperoside or rapamycin treatment alone, indicating that hyperoside had a synergistic effect on induction of autophagy with rapamycin. It has been reported that rapamycin inhibits mTORC1 but regulates Akt via negative feedback, resulting in enhancement of Akt phosphorylation at Ser $473^{[46]}$. These results suggested that hyperoside-induced autophagy in A549 cells was associated with the inhibition of the PI3K/Akt/mTOR signaling pathway.

It is well known that the ERK1/2 pathway is involved in the regulation of autophagy ${ }^{[4]}$. Therefore, we examined whether hyperoside increases the phosphorylation of ERK1/2. The results showed that treatment with hyperoside increased the protein level of phosphorylated ERK1/2. To further clarify whether hyperoside-induced autophagy was connected with phospho-ERK1/2 activation, A549 cells were pretreated with U0126 and then treated with or without hyperoside. Notably, we found that U0126 mildly reversed the levels of LC3-II/ actin ratio.

Autophagy inhibition is important in clarifying the effects of autophagy. A class III PI3K inhibitor, 3-MA, is extensively used as an autophagy inhibitor. To investigate whether autophagy induced by hyperoside has cytoprotective effect or leads to cell death, we treated A549 cells with hyperoside in the presence or absence of 3-MA. We performed an autophagy suppression experiment with 3-MA at $2 \mathrm{mmol} / \mathrm{L}$. Treatment with $2 \mathrm{mmol} / \mathrm{L} 3-\mathrm{MA}$ significantly decreased the percentage of cell death caused by hyperoside treatment $(2 \mathrm{mmol} / \mathrm{L})$, suggesting hyperoside-induced autophagy is not protective in these cell lines and leads to cell death.

Autophagy itself can induce cell death, a process known as autophagic cell death ${ }^{[48]}$. It has also been reported that induction of autophagy facilitates the activation of apoptosis ${ }^{[49]}$. Autophagy and apoptosis often occur in the same cell, generally in a sequence in which autophagy precedes apoptosis. To test whether hyperoside induces apoptosis, we examined the protein expressions of cleaved caspase- 3 and cleaved PARP. Caspase-3 is the most important executioner protein of apoptosis, and PARP is the main substrate of caspase-3. Thus, the activation of caspase- 3 and PARP proteins is commonly considered the biochemical hallmarks of apoptosis. The results of our study indicate that increased concentrations of hyperoside cause a concentration-dependent increase in cleaved caspase- 3 and cleaved PARP. Interestingly, when hyperosideinduced autophagy is blocked by 3-MA treatment, apoptosis is partially attenuated. The cross-talk between apoptosis and autophagy is complex. It has been reported that autophagosome formation has been implicated in the activation of caspase-8. In this context, caspase-8 forms a complex with the death receptor adaptor protein FAS-associated death domain (FADD) and ATG5, colocalizes with ATG5, LC3 and SQSTM1 and is activated in an ATG5-, FADD- and SQSTM1-dependent manner ${ }^{[50]}$. In addition, autophagy may also stimulate apoptosis by depleting endogenous inhibitors of this cell death pathway ${ }^{[51]}$. These results provide new insight into the effects of hyperoside on cell death and suggest a possible intervention strategy for the upregulation of apoptosis by harnessing of its autophagic activity in tumor treatment.

In conclusion, our experiments provided the first evidence that hyperoside promoted autophagy and possesses anticancer functions through inhibiting the Akt/mTOR/p70S6K signaling pathway in NSCLC cells. The results of this study merit further investigation for the development of hyperoside as an anti-cancer agent.

\section{Acknowledgements}

This work was supported by grants from the Natural Science Foundation of Liaoning Province, China (№ 2013022008).

\section{Author contribution}

Ying JIN and Ling WANG designed the research; Ting FU, Xiang-nan JIN, Hai-juan SUI, and Zhou LIU performed the research; Ting FU and Hai-juan SUI analyzed the data; and Ying JIN wrote the paper.

\section{References}

1 Yuan J, Horvitz HR. A first insight into the molecular mechanisms of apoptosis. Cell 2004; 116: S53-6, 1 p following S59.

2 Nicholson DW, Ali A, Thornberry NA, Vaillancourt JP, Ding CK, Gallant $\mathrm{M}$, et al. Identification and inhibition of the ICE/CED-3 protease necessary for mammalian apoptosis. Nature 1995; 376: 37-43.

3 Farias A, Cabrerizo M, Re V, Glatstein N, Pisano B, Spinsanti L, et al. Molecular identification of human enteroviruses in children with neurological infections from the central region of Argentina. Arch Virol 2011; 156: 129-33.

4 Liang XH, Jackson S, Seaman M, Brown K, Kempkes B, Hibshoosh H, et al. Induction of autophagy and inhibition of tumorigenesis by beclin 1. Nature 1999; 402: 672-6.

5 Eisenberg-Lerner A, Bialik S, Simon HU, Kimchi A. Life and death partners: apoptosis, autophagy and the cross-talk between them. Cell Death Differ 2009; 16: 966-75.

6 Mathew R, Karp CM, Beaudoin B, Vuong N, Chen G, Chen HY, et al. Autophagy suppresses tumorigenesis through elimination of p62. Cell 2009; 137: 1062-75.

7 Espert L, Denizot M, Grimaldi M, Robert-Hebmann V, Gay B, Varbanov $\mathrm{M}$, et al. Autophagy is involved in T cell death after binding of HIV-1 envelope proteins to CXCR4. J Clin Invest 2006; 116: 2161-72.

8 Kroemer G, Galluzzi L, Vandenabeele P, Abrams J, Alnemri ES, Baehrecke $\mathrm{EH}$, et al. Classification of cell death: recommendations of 
the Nomenclature Committee on Cell Death 2009. Cell Death Differ 2009; 16: 3-11.

9 Hayashi-Nishino M, Fujita N, Noda T, Yamaguchi A, Yoshimori T, Yamamoto A. A subdomain of the endoplasmic reticulum forms a cradle for autophagosome formation. Nat Cell Biol 2009; 11: 1433-7.

10 Ravikumar B, Moreau K, Rubinsztein DC. Plasma membrane helps autophagosomes grow. Autophagy 2010; 6: 1184-6.

11 Yang ZJ, Chee CE, Huang S, Sinicrope F. Autophagy modulation for cancer therapy. Cancer Biol Ther 2011; 11: 169-76.

12 Hennessy BT, Smith DL, Ram PT, Lu Y, Mills GB. Exploiting the PI3K/ AKT pathway for cancer drug discovery. Nat Rev Drug Discov 2005; 4: 988-1004.

13 Jung $\mathrm{CH}$, Ro SH, Cao J, Otto NM, Kim DH. mTOR regulation of autophagy. FEBS Lett 2010; 584: 1287-95.

14 Shigemitsu K, Tsujishita Y, Hara K, Nanahoshi M, Avruch J, Yonezawa K. Regulation of translational effectors by amino acid and mammalian target of rapamycin signaling pathways. Possible involvement of autophagy in cultured hepatoma cells. J Biol Chem 1999; 274: 1058-65.

15 Chen M, Du Y, Qui M, Wang M, Chen K, Huang Z, et al. Ophiopogonin B-induced autophagy in non-small cell lung cancer cells via inhibition of the PI3K/Akt signaling pathway. Oncol Rep 2013; 29: 430-6.

16 Aoki H, Takada Y, Kondo S, Sawaya R, Aggarwal BB, Kondo Y. Evidence that curcumin suppresses the growth of malignant gliomas in vitro and in vivo through induction of autophagy: role of Akt and extracellular signal-regulated kinase signaling pathways. Mol Pharmacol 2007; 72: 29-39.

17 Ellington AA, Berhow MA, Singletary KW. Inhibition of Akt signaling and enhanced ERK1/2 activity are involved in induction of macroautophagy by triterpenoid B-group soyasaponins in colon cancer cells. Carcinogenesis 2006; 27: 298-306.

18 Granville CA, Warfel N, Tsurutani J, Hollander MC, Robertson M, Fox $\mathrm{SD}$, et al. Identification of a highly effective rapamycin schedule that markedly reduces the size, multiplicity, and phenotypic progression of tobacco carcinogen-induced murine lung tumors. Clin Cancer Res 2007; 13: 2281-9.

19 Middleton E Jr, Kandaswami C, Theoharides TC. The effects of plant flavonoids on mammalian cells: implications for inflammation, heart disease, and cancer. Pharmacol Rev 2000; 52: 673-751.

20 Zou Y, Lu Y, Wei D. Antioxidant activity of a flavonoid-rich extract of Hypericum perforatum L in vitro. J Agric Food Chem 2004; 52: 5032-9.

21 Li HB, Yi X, Gao JM, Ying XX, Guan HQ, Li JC. The mechanism of hyperoside protection of ECV-304 cells against tert-butyl hydroperoxide-induced injury. Pharmacology 2008; 82: 105-13.

22 Li FR, Yu FX, Yao ST, Si YH, Zhang W, Gao LL. Hyperin extracted from Manchurian rhododendron leaf induces apoptosis in human endometrial cancer cells through a mitochondrial pathway. Asian Pac J Cancer Prev 2012; 13: 3653-6.

23 Yang FQ, Liu M, Li W, Che JP, Wang GC, Zheng JH. Combination of quercetin and hyperoside inhibits prostate cancer cell growth and metastasis via regulation of microRNA21. Mol Med Rep 2015; 11 : 1085-92.

$24 \mathrm{Kim}$ SJ, Um JY, Lee JY. Anti-inflammatory activity of hyperoside through the suppression of nuclear factor-kappaB activation in mouse peritoneal macrophages. Am J Chin Med 2011; 39: 171-81.

25 Ku SK, Zhou W, Lee W, Han MS, Na M, Bae JS. Anti-inflammatory effects of hyperoside in human endothelial cells and in mice. Inflammation 2015; 38: 784-99.

26 Ku SK, Kwak S, Kwon OJ, Bae JS. Hyperoside inhibits high-glucoseinduced vascular inflammation in vitro and in vivo. Inflammation
2014; 37: 1389-400.

27 Li W, Liu M, Xu YF, Feng Y, Che JP, Wang GC, et al. Combination of quercetin and hyperoside has anticancer effects on renal cancer cells through inhibition of oncogenic microRNA-27a. Oncol Rep 2014; 31: 117-24.

28 Munafo DB, Colombo MI. A novel assay to study autophagy: regulation of autophagosome vacuole size by amino acid deprivation. J Cell Sci 2001; 114: 3619-29.

29 Zhang LL, Sui HJ, Liang B, Wang HM, Qu WH, Yu SX, et al. Atorvastatin prevents amyloid-beta peptide oligomer-induced synaptotoxicity and memory dysfunction in rats through a p38 MAPK-dependent pathway. Acta Pharmacol Sin 2014; 35: 716-26.

30 Mizushima N, Yoshimori T. How to interpret LC3 immunoblotting. Autophagy 2007; 3: 542-5.

31 Pankiv S, Clausen TH, Lamark T, Brech A, Bruun JA, Outzen H, et al. p62/SQSTM1 binds directly to Atg8/LC3 to facilitate degradation of ubiquitinated protein aggregates by autophagy. J Biol Chem 2007; 282: 24131-45.

32 Mizushima N, Yoshimori T, Levine B. Methods in mammalian autophagy research. Cell 2010; 140: 313-26.

33 Takeuchi H, Kondo Y, Fujiwara K, Kanzawa T, Aoki H, Mills GB, et al. Synergistic augmentation of rapamycin-induced autophagy in malignant glioma cells by phosphatidylinositol 3-kinase/protein kinase B inhibitors. Cancer Res 2005; 65: 3336-46.

34 Garami A, Zwartkruis FJ, Nobukuni T, Joaquin M, Roccio M, Stocker $\mathrm{H}$, et al. Insulin activation of Rheb, a mediator of mTOR/S6K/4E-BP signaling, is inhibited by TSC1 and 2. Mol Cell 2003; 11: 1457-66.

35 Inoki K, Li Y, XU T, Guan KL. Rheb GTPase is a direct target of TSC2 GAP activity and regulates mTOR signaling. Genes Dev 2003; 17 : 1829-34.

36 Levine B, Klionsky DJ. Development by self-digestion: molecular mechanisms and biological functions of autophagy. Dev Cell 2004; 6 : 463-77.

37 Seglen PO, Gordon PB. 3-Methyladenine: specific inhibitor of autophagic/lysosomal protein degradation in isolated rat hepatocytes. Proc Natl Acad Sci U S A 1982; 79: 1889-92.

38 Rubinsztein DC, Gestwicki JE, Murphy LO, Klionsky DJ. Potential therapeutic applications of autophagy. Nat Rev Drug Discov 2007; 6: 304-12.

39 Dalby KN, Tekedereli I, Lopez-Berestein G, Ozpolat B. Targeting the prodeath and prosurvival functions of autophagy as novel therapeutic strategies in cancer. Autophagy 2010; 6: 322-9.

40 Gao LL, Feng L, Yao ST, Jiao P, Qin SC, Zhang W, et al. Molecular mechanisms of celery seed extract induced apoptosis via s phase cell cycle arrest in the BGC-823 human stomach cancer cell line. Asian Pac J Cancer Prev 2011; 12: 2601-6.

41 Chen S, Rehman SK, Zhang W, Wen A, Yao L, Zhang J. Autophagy is a therapeutic target in anticancer drug resistance. Biochim Biophys Acta 2010; 1806: 220-9.

42 Pattingre S, Espert L, Biard-Piechaczyk M, Codogno P. Regulation of macroautophagy by mTOR and Beclin 1 complexes. Biochimie 2008; 90: 313-23.

43 Kabeya Y, Mizushima N, Ueno T, Yamamoto A, Kirisako T, Noda T, et al. LC3, a mammalian homologue of yeast Apg8p, is localized in autophagosome membranes after processing. EMBO J 2000; 19: 5720-8.

44 Mao JH, Kim IJ, Wu D, Climent J, Kang HC, DelRosario R, et al. FBXW7 targets mTOR for degradation and cooperates with PTEN in tumor suppression. Science 2008; 321: 1499-502.

45 Vivanco I, Sawyers CL. The phosphatidylinositol 3-kinase AKT pathway in human cancer. Nat Rev Cancer 2002; 2: 489-501. 
46 Wan X, Harkavy B, Shen N, Grohar P, Helman $\sqcup$. Rapamycin induces feedback activation of Akt signaling through an IGF-1R-dependent mechanism. Oncogene 2007; 26: 1932-40.

47 Ogier-Denis E, Pattingre S, El Benna J, Codogno P. Erk1/2-dependent phosphorylation of Galpha-interacting protein stimulates its GTPase accelerating activity and autophagy in human colon cancer cells. J Biol Chem 2000; 275: 39090-5.

48 Lamy L, Ngo VN, Emre NC, Shaffer AL 3rd, Yang Y, Tian E, et al. Control of autophagic cell death by caspase-10 in multiple myeloma. Cancer Cell 2013; 23: 435-49.

49 Marino G, Niso-Santano M, Baehrecke EH, Kroemer G. Self- consumption: the interplay of autophagy and apoptosis. Nat Rev Mol Cell Biol 2014; 15: 81-94.

50 Young MM, Takahashi Y, Khan O, Park S, Hori T, Yun J, et al. Autophagosomal membrane serves as platform for intracellular deathinducing signaling complex (iDISC)-mediated caspase-8 activation and apoptosis. J Biol Chem 2012; 287: 12455-68.

51 Nezis IP, Shravage BV, Sagona AP, Johansen T, Baehrecke EH, Stenmark H. Autophagy as a trigger for cell death: autophagic degradation of inhibitor of apoptosis dBruce controls DNA fragmentation during late oogenesis in Drosophila. Autophagy 2010; 6: 1214-5. 